\title{
PEOPLE, PROCESS, TECHNOLOGY IN CONSTRUCTION 4.0 - BALANCING KNOWLEDGE, DISTRUST AND MOTIVATIONS
}

\author{
Pedro Mêda ${ }^{1}$, Hipólito Sousa ${ }^{2}$, Miguel Gonçalves ${ }^{3}$, Diego Calvetti $^{4}$, Paulo Dias ${ }^{5}$ and \\ Fernando Camargo ${ }^{6}$
}

\begin{abstract}
Construction sector digital transformation is an ongoing task engaged by the urgent goals of a more sustainable, efficient and competitive industry. Construction embraces these challenges quite behind. Given its unique environment, the success of transformation actions is fundamental. People, process and technology are essential analysis dimensions of the productive chain and involved parties. The outcomes and success measurement of these initiatives require advanced insights in order to strategically target the actions.

The present research contributes with tools for improved approaches to digital transformation initiatives, providing a framework to perform assessments and obtain a streamlined awareness of stakeholder's perceptions, motivations and confidence regarding one or more supporting principles of the Construction 4.0 vision. The development was based on state-of-the-art viewpoint and analysis of specific digital transformation initiatives. The framework output assumes the format of a survey. This was circulated on the context of post-graduate training actions. The motivation was achieving, for a specific type of stakeholder and context, a global picture regarding digital transformation impressions in its dimensions.

The findings evidence that "Technological dimension" is, in general, more mature than the others, meaning that efforts must concentrate on people motivations and added value of the transformation at "process level".
\end{abstract}

Keywords: Strategy, Digital Transformation, Management, Success, Stakeholders

\section{INTRODUCTION}

Construction is one of the first businesses that humankind developed, and it continues to shape our daily life in unique ways (Forum, 2016). The relevance of the industry can be observed on the built environment and how it affects the society and the landscape. The CI - Construction Industry is therefore crucial at societal, economic and environmental levels (Commission, 2012). Due to or despite this relevance, the industry has changed few over the years, namely when compared with other economic activities. This situation has been studied in different countries (Egan, 2000) (Richardson, 2014) and it can be stated that it is a common and worldwide issue, rather than a situation from a

MSc Eng., Construction Institute, CONSTRUCT - FEUP, Porto, Portugal, pmeda@fe.up.pt Associate Professor, PhD Eng., CONSTRUCT - FEUP, Porto, Portugal, hipolito@fe.up.pt Assistant Professor, PhD Eng., CONSTRUCT - FEUP, Porto, Portugal, miguelcg@fe.up.pt PhD Candidate, Eng., CONSTRUCT - FEUP, Porto, Portugal, diego.calvetti@fe.up.pt Professor, Eng., Brazilian Cost Engineering Council, Rio de Janeiro, Brazil, paulodias@ibec.org.br Professor, Eng., Brazilian Cost Engineering Council, Rio de Janeiro, Brazil, fernandocamargo@ibec.org.br 
specific geography or single country (KMPG-PMI, 2013). Construction productivity has been increasing performance over the years, but at a rate that is nearly four times inferior to the observed in manufacturing industries. This behaviour impacts not only the competitiveness, but mainly the sustainability at economic and environmental levels. Construction is ripe for transformation and Industry 4.0 drivers are envisaged as enablers towards a more efficient, sustainable and competitive sector, shaping its pace in a route to higher productivity (Sriram Changali, Azam Mohammad, 2015).

Industry 4.0 paradigm stem from the 4th industrial revolution, where digitalization and cyber-physical systems (Desruelle et al., 2019) follow earlier revolutions based on mechanization, electrification and automation, respectively (Turk, 2019). The European Construction Industry Federation wrote in its manifesto: "Construction 4.0 is our branch of Industry 4.0. We use this term to refer to the digitalisation of the CI." (FIEC, 2014)

Therefore the "digital transformation" process relies in technologies and methodologies to introduce digitalization on the value chains setting Digital Twins as the ultimate goal. The same vision is brought to the CI at all levels from products or tasks to facility or built environment levels (CDbb, 2019). In what relates to technologies, the ones presented in Figure 1 have been placed at the forefront for adoption within the CI (PwC Portugal, 2016) (Sousa, H.; Mêda, 2017).

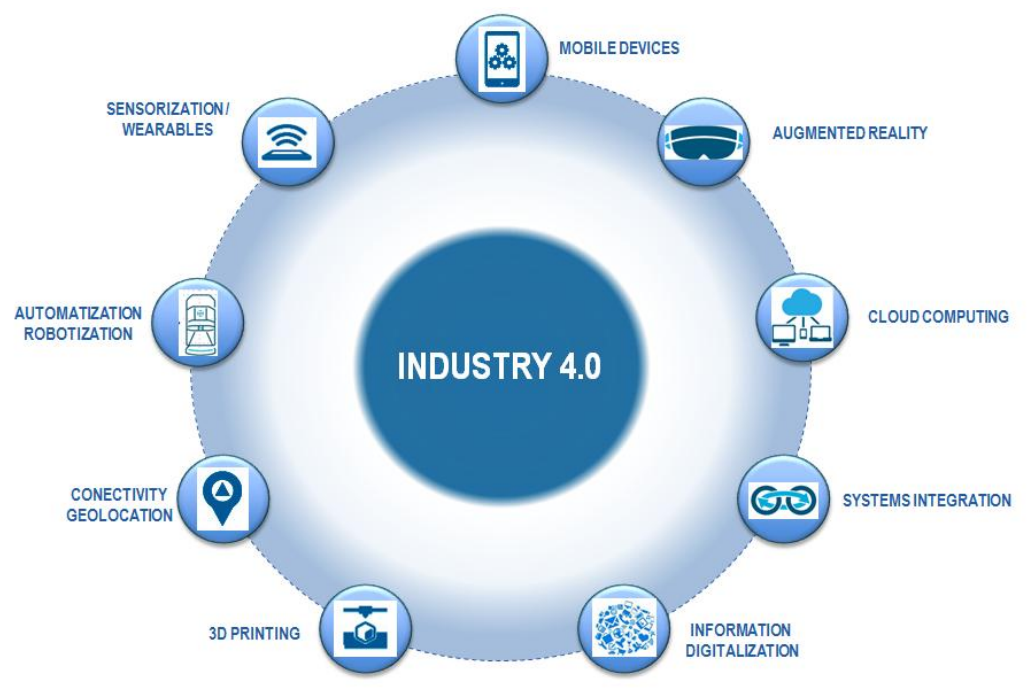

Figure 1: Technologies/Main principles of Industry 4.0 vision (Sousa, H.; Mêda, 2017)

The enthusiastic movements towards digital transformation in construction must understand the unique environment of the sector, the main barriers and the structural characteristics that have been dragging down the innovation adoption rhythm. The Industry Agenda developed by the World Economic Forum summarizes in its Figure 4 some of the main construction characteristics and client context that make the industry unique (Forum, 2016). Some might argue that the industry will not be able to accelerate the pace, as it is required. Without neglect that it will always require more effort and more time to accomplish when compared with other activities, the digital transformation of the CI is feasible and fundamental for the countries' economies, for the built environment and for the natural environment, among others. Spearhead companies, incremental innovation and knowledgeable strategic approaches on implementation 
processes are essential to assure the success of the initiatives, the added value of the achievements and the stakeholders' confidence (Yagiz, Kartal, et al., 2018).

Construction 4.0 challenges have been explored, among others, following the PESTEL framework (Political, Economic, Social, Technologic, Environmental, Legal analysis) (Oesterreich \& Teuteberg, 2016). This approach identifies the main aspects or feelings that stakeholders have when confronted with digital transformation topic in general. This base knowledge can evolve to an analysis more detailed or focused on the activities of the value chain; the processes. This uses two dimensions of the PESTEL framework and adds a third to achieve the innovation imperatives or dimensions proposed by IDDS research roadmap (Owen, 2013). A value chain activities approach is found to be relevant as it provides maturity impressions, readiness model and defines how balanced the dimensions must be in order to strategically draw implementation processes towards the goals/success achievement in a specific initiative.

Digital transformation research activities and reports on implementation processes have been following this approach. BIM adoption strategies dominate the literature due to the relevance and impacts for the industry (Succar \& Kassem, 2015) (Hjelseth, 2017). Collaborative tools (Derenzi et al., 2009) (Martin Fischer, Howard W. Ashcraft, Dean Reed, 2017), 3D printing and more recently Blockchain technology (Ali \& Smith, 2019) are other relevant topics, just to name few.

The evidenced gap between implementation strategies and stakeholders motivations can lead to failure. Worst, is the mind set and preconceptions that stakeholders quickly spread and add to their always existing resistance to change (Calvetti, et al., 2019) (Fischer, et al., 2017). The motivation for the present research comes from the daily challenges in raising the bar of the industry towards the adoption of innovations and from the experience of managing digital transformation processes at large scale in a public institutions (construction owners) ranging the construction process from design until end construction and linking with facility management. The process was continuous during 3 years and had a successful implementation (Sousa, H.; Mêda, 2016). The initial strategies targeted for technological aspects were rapidly shifted to personal and process based strategies. The technological dimension was introduced as a problem solver and a way to streamline processes and fulfil requirements (new and existing ones that were not accomplish on projects) (Rasmus Rempling, Esra Kurul, 2019). The lessons learn from this experience raise on the team the awareness for the "fineness" of achieving successful digital transformation processes in the CI.

\section{RESEARCH OBJECTIVES AND CONTRIBUTIONS TO THE BODY OF KNOWLEDGE}

Higher competitiveness, sustainability and efficiency are goals for the CI. Digitalization, as stated, is a megatrend and a driver towards those objectives. How can companies and stakeholders take the best steps and the best advantage from the implementation of new technologies in order to accomplish their own goals and the industry challenges?

The digital transformation of the CI is more sensitive than in other economic activities due to its unique environment, specificities and broadness (Forum, 2016).

The research frames on the difficulties on achieving the best benefits or at least a successful evaluation of these processes. Every effort to implement new technologies or processes must be strategically defined and targeted for the added value that can bring to the industry at personal, corporate and construction process levels. In addition, the 
innovative actions cannot bring more effort to the stakeholders, namely if this relies on the manual introduction of the same data in different tools. A less successful implementation of innovations can promote severe preconceptions and mind sets that will become very difficult to overcome. The introduction of innovation processes must rely on approaches that evaluate dimensions as People, Process and Technology. The success or failure of the process depends on the delicate balance of these aspects in accordance with the stakeholders and companies involved.

The objective of the research is to raise awareness for the sensitivity on the preparation of innovative actions that contribute to the construction digital transformation and provide tools to support and obtain, at early stages, an improved awareness of the perceptions, preconceptions, doubts and weaknesses of the stakeholders facing the process. This information is found to be extremely useful as decreases the gap between the technology to be implemented/adopted and the adopters. The development of knowledgeable strategic approaches can contribute to the success rate improvement of digital transformation processes in the CI.

Despite the fact the outcomes impact all industry stakeholders, these are assumed, at this point, to be more relevant to Corporate Directors, Managers and Consultancy in Innovation, to gain awareness and define the best roadmaps and strategies regarding the positioning of a company, its objectives and best select the early adopters or the "transformation team".

\section{Methodology}

The sensitivity of implementing innovative actions in construction is not a new subject and, as stated, many authors have been addressing their studies to this topic. Yet, many are more focused in specific technologies or methodologies. The state-of-the-art viewpoint allowed the identification of references to constitute a background for this broad approach.

The objective was to achieve a global perspective of stakeholders facing CI digital transformation using as starting point Industry 4.0 main technologies. Consequently, a review on strategic documents towards Industry 4.0 and Construction 4.0 was required.

These were combined with the "Imperatives" or dimensions of the IDDS research roadmap to enable/foster a multifaceted opinion of the stakeholders regarding a defined technology and perceptions of its usability both by people in construction, as well as a tool to support construction processes/tasks across the value chain.

To achieve organized and compiled data the framework was transposed to a survey. This is composed by two parts. The first is where respondents select for each technology at "technology", "process" and "people" dimensions the maturity in accordance with a four scale option: "1- Emerging; 2-Sedimented; 3-Generalized; 4-Consolidated". This provides the maturity levels for each technology in each dimension. The second part is composed by an essay question where respondents select and develop an explanation of the reasons, motivations and visions/opinions that led to the identification of the maturity levels on the previous question. The challenge was to select and develop justification for two technologies.

The survey provides both global and detailed vision of stakeholder's opinions/knowledge regarding digital transformation technologies.

The questions and schema of the survey are presented in the following section. To test the framework and perform a first analysis of the potential results, the survey was used as part of the activities of a post-graduate training action delivered using e-learning. 

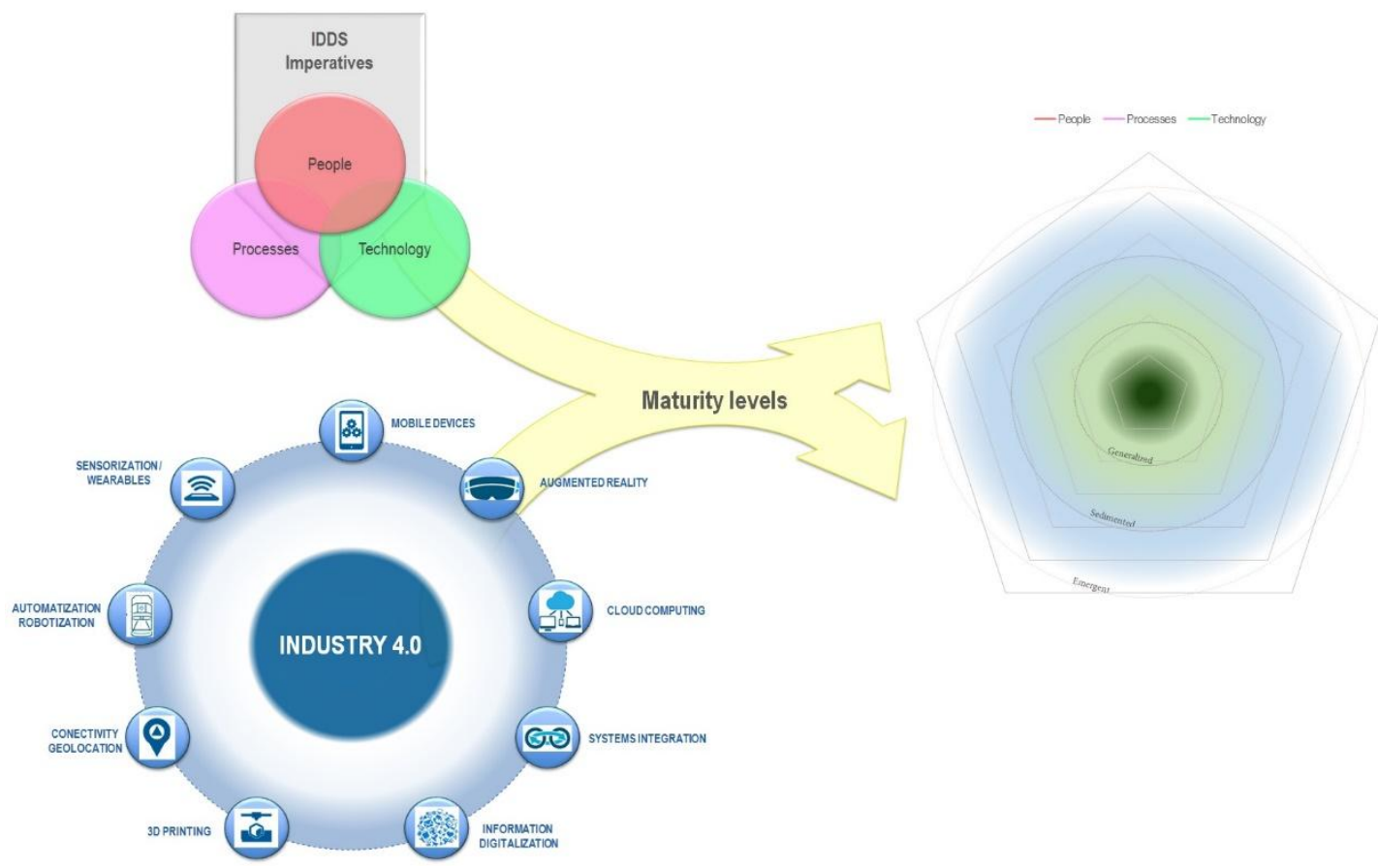

Figure 2: Elements and their combination to achieve the visual outcome of the framework.

\section{DEVELOPMENT}

\subsection{Survey}

As presented in Figure 2, the framework comes from Construction 4.0 main technologies combined with IDDS innovation dimensions and four maturity levels established for the purpose of the survey, providing four possible selection fields. The first question aimed quick and broad stakeholder's opinions regarding the technologies, its use in construction processes and knowledge/empathy of these technologies at a personal level. The question and table are the following:

"For an innovation process to succeed it is necessary to find a balance between dimensions such as technology, processes and people. Construction sector digitalization megatrends are based in some technologies. The purpose of this question is to understand your personal view as construction stakeholder of the maturity of different technologies in the industry, the maturity of their use in construction processes/tasks and the knowledge/empathy of the construction stakeholders for their use. Identify for each situation the maturity level that fits better your vision."

The second question is an essay where an introduction/guideline is presented to exemplify the type of intended answer. "Mobile devices" technology was used as example because it was found to be the one that could be easily understood by all students.

"Following the development of the previous table, perform an essay based on one or two technologies (other than mobile devices) where you detail the reasons for selecting the 
maturity levels in the different dimensions. The text above exemplifies the type of intended answer:"

"In terms of technology, the opinion is that "mobile devices" have a "Consolidated" maturity, as most of the construction industry stakeholders use mobile phones, tablets, others, on a daily basis either for work or personal purposes. People have empathy to the mobile devices and, at personal level, there is a "Generalized" maturity regarding the knowledge on the basic tools and their use, namely phone, agenda, camera, Internet access. The use of mobile devices to support construction processes is the dimension that is less mature. There are several applications (apps) and mobile devices functionalities that are already used to support construction processes. Yet, the range and full potential of these devices for the processes in construction have still a lot to accomplish. Given this, the maturity at process level can be considered as "Emergent"."

Table 1: Table for respondents to mark their opinion in terms of maturity levels

\begin{tabular}{|c|c|c|c|c|}
\hline Technologies/Dimensions & $\begin{array}{l}\text { Maturity } \\
\text { Emergent }\end{array}$ & Sedimented & Generalized & Consolidated \\
\hline \multicolumn{5}{|l|}{ TECHNOLOGY } \\
\hline $\begin{array}{l}\text { Mobile devices (smartphone, tablet, } \\
\text { others) } \\
\text { Augmented Reality } \\
\text { Cloud computing } \\
\text { Systems integration/interoperability } \\
\text { Information digitalization / metadata } \\
\text { 3D printing } \\
\text { Connectivity } \\
\text { Automatization/Robotization } \\
\text { Sensorization/Wearables }\end{array}$ & & & & \\
\hline \multicolumn{5}{|l|}{ PEOPLE } \\
\hline $\begin{array}{l}\text { Mobile devices (smartphone, tablet, } \\
\text { others) } \\
\text { Augmented Reality } \\
\text { Cloud computing } \\
\text { Systems integration/interoperability } \\
\text { Information digitalization / metadata } \\
\text { 3D printing } \\
\text { Connectivity } \\
\text { Automatization/Robotization } \\
\text { Sensorization/Wearables }\end{array}$ & & & & \\
\hline \multicolumn{5}{|l|}{ PROCESSES } \\
\hline $\begin{array}{l}\text { Mobile devices (smartphone, tablet, } \\
\text { others) } \\
\text { Augmented Reality } \\
\text { Cloud computing } \\
\text { Systems integration/interoperability } \\
\text { Information digitalization / metadata } \\
\text { 3D printing } \\
\text { Connectivity } \\
\text { Automatization/Robotization } \\
\text { Sensorization/Wearables }\end{array}$ & & & & \\
\hline
\end{tabular}

This example of essay was just to express one opinion and the maturities were defined based on authors feelings and knowledge with the consciousness that it could influence some of the results, namely in terms of this technology. This was one of the other reasons to perform a guideline essay using mobile devices and not any other technology. 


\subsection{Case Study - Samples}

As mentioned, the results were obtained through the development of surveys that circulated as part of the activities of a post-graduate action in construction management specially designed for architecture and engineering professionals. This action was structured by the institutions where the authors belong and it was delivered mainly to Brazilian professionals. The first action took place in 2018 and the second on the following year. There were 52 and 45 valid surveys, respectively, performing 97 answers. This sample, despite the considerable dimension, is narrow, when compared to the size of the Brazilian CI and its stakeholders.

Nevertheless, the results, as detailed further, are found to draw a very good picture of the awareness and perceptions of this group of stakeholders (design team members, managers and construction/field directors - architecture and engineering professionals (Desruelle et al., 2019)) regarding the digital transformation of the industry.

As part of the survey, the essay or detailed explanation was asked to all students in order to obtain more insights. This information is found essential to have a more clear perspective of stakeholder's knowledge, understanding and feelings. The next subsection presents an analysis of the results and is supported with the transcription of some answers.

\subsection{Results}

Given the opportunity to work with two samples with similar characteristics, same country, same type of stakeholder and similar size, it is possible to perform analysis at different levels. Therefore, this part explores the results of each survey individually and to what is found to be the best balance between the different dimensions for each technology. In parallel, insight is performed regarding the most mature technologies, when facing a direct comparison process. Respondents' visions were used to support some of the results. The section "Discussions and Findings" will concentrate more on a global vision of the results from the two surveys, setting a way for the conclusions where future headings are explored. Figure 3 systematizes the results of the 2018 survey. 


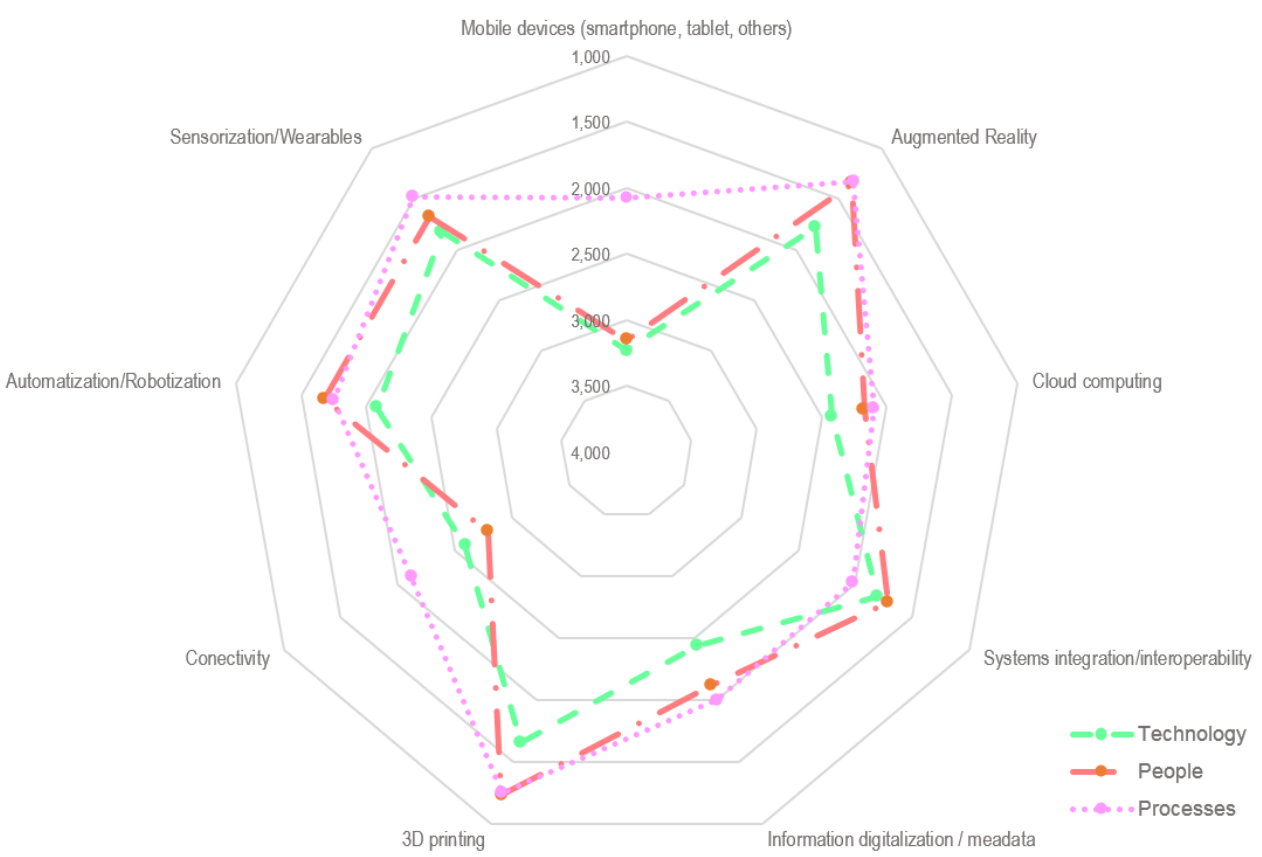

Figure 3: 2018 survey results

As it is possible to observe, the technology that evidenced high maturity in terms of the "technological dimension" is "Mobile Devices", followed at distance and with similar results by "Connectivity", "Information digitalization" and "Cloud computing". "3D printing" is the technology that registered a lower maturity level, not only in the "technological dimension" but also in others and is closely followed by "Augmented Reality". Insights from respondent's essays detail the reasons for these results. Influenced or not by the example presented on the survey, "Mobile Devices" evidences at "process dimension" a significant lower maturity level when compared with the other dimensions. In fact, this is the technology where the highest maturity gap is observed between the different dimensions. In opposition, "Systems integration/interoperability" is the technology where the three dimensions evidence less deviation.

In most technologies, the "technological dimension" is ahead of the others, exception made for "Systems integration/interoperability", where the "process dimension" is found to be the more mature and for "Connectivity" where "personal dimension" registers the higher maturity.

These cases find interesting justifications on the type of stakeholders' that answered the survey. Architecture and Engineering professionals are skilled and knowledgeable of the impacts that "Systems integration/interoperability" have in their value chain processes. The technologies to accomplish are still lacking in fulfilling all the aims. Digital transformation strategies, at this level, should use processes knowledge to help drawing improved technological solutions. "Systems integration" is a subject that always raises issues related with resistance to change (Fischer, et al., 2017). Therefore, the achieved results for the "personal dimension" are far from being strange. Given this picture, the implementation strategies must approach "People" from the "Process" side, working misunderstandings, reluctances and fears.

The opposite is evidenced with "Connectivity". This can indicate that at "People dimension" the stakeholders' know and deal well with the technology, in part because it is partially embedded in "mobile devices" (the results are similar at people dimension), but when it comes to use it in construction processes there is a lack of understanding of the applications. The approach should focus then on the processes where this technology 
can be used. Two examples of respondents' essay on the above mentioned technologies help to support the visions:

“" $3 D$ printing” is a very well-known technology in Brazil. Despite this fact, the scenario in terms of the construction industry changes. The notion is that is a promising technology with many potential applications both on large and small projects, as well as for the production of building/infrastructure parts. The feeling is that in a near future the use of this technology will increase significantly within the CI. Given this, and for the present moment, I find "3D printing" "Sedimented" at technological level given the influence and knowledge from other uses outside construction. At People and Process level the technology can be considered "Emergent" as the uses, applications and knowledge stills lacks. Stakeholders are concerned, at the moment, with tools to support other processes."

"Augmented reality" is still an "Emerging" technology, namely at people and process levels. The technology is known from other sectors, namely entertainment and gaming. "Augmented reality" in the CI can have many different applications, most of them glued to an advanced visualization of BIM. This means that in order to become more used it has to be integrated with BIM and follow up its implementation that it is still not widespread. Its use in construction is at the moment narrowed to sales and marketing processes but few companies are running it due to the required investments."

The 2019 survey results are systematized in Figure 4. The sequence of the three dimensions in each technology is the same registered in 2018 with exception to "Systems integration/interoperability" where the "process dimension" is surpassed by the "technological dimension" and "Connectivity" where the "technological dimension" falls behind assuming the position of the less mature dimension.

It is interesting to highlight that these exceptions occur in the technologies where in 2018, the "technological dimension" was not the one where higher maturity was registered. The deviations between the dimensions are in general lower in the 2019 survey and the lowest was registered in "Augmented Reality". The results of the essays' on this technology are therefore interesting to explore as it follows: 


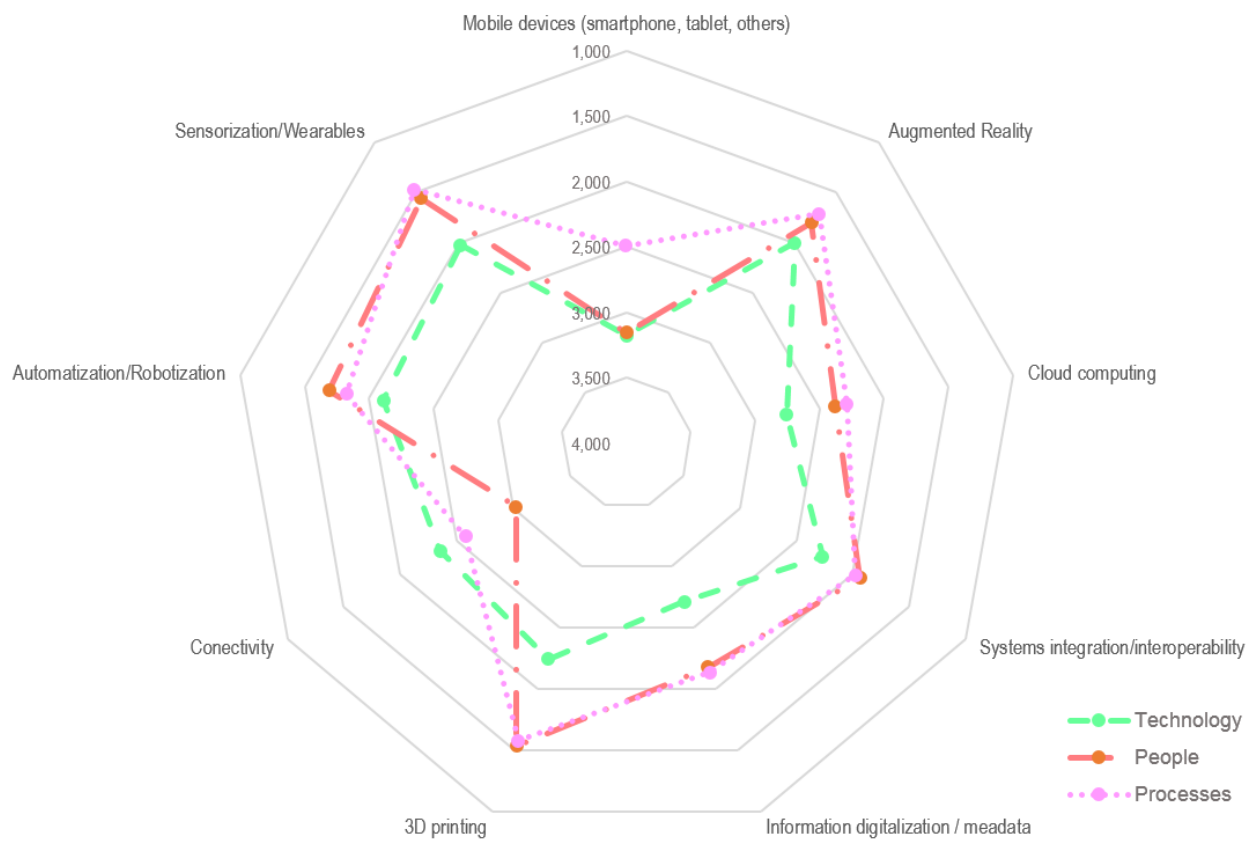

Figure 4: 2019 survey results.

"It is my feeling that "Augmented Reality" is evolving and expanding rapidly. This technology is being more and more adopted to support the design process as it allows professionals to take advantage of the visualization potential to identify problems prior to construction, allowing their correction. This streamlines and speeds up the construction stage as well as contributes to the quality of the final product. At "people level" stakeholders understand that this is a tools that raises efficiency and supports decisions. Interfaces and training for improved design processes are key."

From this answer it is possible to identify a shift on the main uses of this technology. In addition to marketing and sales "Augmented Reality" gains relevance as a tool to support improved design processes.

In opposition "3D printing" is the technology where higher dispersion between the three dimensions was observed, namely if we compare "People and Process" dimensions (nearly the same maturity; barely "emergent") with "Technology" dimension that is considered "sedimented".

Again, due to this results it is interesting to look in detail to the respondents essays on this subject, namely the ones that add some to what was stated on the 2018 survey:

“" $3 D$ printing” is a technology with many applications in several economic activities. This promotes a broad knowledge of its potential uses, even within the construction. Therefore, the knowledge can be considered "sedimented" at "technology" dimension. The implementation costs are high and require a reconfiguration of processes and practices. This is the experience from other industries and construction will be no exception. And this can be the main obstacle and a reason to consider that at "people and process" dimensions the maturity is still "emergent". There are large applications off-site and integrated on scientific experiences, yet, on site it will be challenging on the following years as processes and practices are fragmented and diverse. Situation might change if the technology cost decreases and small companies appear providing specific advanced construction services or solutions using this technology." 
"Automation/Robotization", "Sensorization/Wearables", as well as previously mentioned "3D printing" are the technologies where it can be observed at "people and process dimensions" the lower maturity levels. This can find justification with the concerns and role of the inquired stakeholders' on the construction value chain. This can be confirmed again looking to the essay answers and respondents profile. Without placing a single translation of one answer and considering answers overview, there are some respondents that address to these two technologies, mainly if they have a role during construction, namely field director. One of the most interesting answers stated that the fragmented value chain of the construction industry, even at activities level, prevents the generalization of "Automation/Robotization". A field for this technology in construction might come with the advances of autonomous vehicles and the adaptation to site equipment's. And this is one interesting touch-point with "Sensorization/Wearables" as some essays state that the use of this technology is more mature outside the industry where people use sensors combined with other technologies for daily purposes, as running or others. Notwithstanding, the use of sensors by field equipment's and workers to control their position on site (safety issues) is identified as the gateway for the implementation of the technology within the industry.

\section{DisCUSSION AND Findings}

The results from the two surveys evidences an alignment that surprised the authors. In all technologies and for the three dimensions it was observed, in terms of maturity, the same results or evolutions. One single exception worth's to be highlighted that is the "people dimension" in "Sensorization". This registered a slight setback that can be justified with the type of stakeholder that answered the survey.

The evolutions can be considered natural and reveal that awareness actions on digital transformation are taking effect in particular for the case of this type of stakeholders.

The survey results can be highly influenced by the type of stakeholder, meaning that different technologies will reveal different maturity levels at all dimensions depending on the role.

A situation that worth's to follow up is the behaviour of the results within the same type of stakeholder but facing different contexts, namely countries.

Architecture and Engineering professionals are found to evidence more knowledge/concern for some technologies. The results express that "Cloud computing", "Information digitalization/metadata" and "Connectivity" are the technologies where in all dimensions the maturity levels are higher. Follows "System integration/interoperability" and "Augmented reality". One identifiable reason for these results can be the fact that these technologies are closest to the respondent's daily processes. Respondents' essays confirm this statement as many state that "cloud technologies" are daily used to share documents and applications at different stages of the construction process. This type of technology also fosters mobility as the same person can have access to documents in different places and using different interfaces (PC, mobile, tablet, others).

When looking in detail for the perspective of each technology, it is possible to see that the readiness and the implementation strategies must vary and meet the stakeholders' feelings.

The dimension that evidences less maturity is the one that will lead the entire strategic design of the digital transformation process. Through the understanding of the 
why it is possible to set a roadmap and milestones to overcome step by step the difficulties, improving the chances for positive outcomes.

The results provide a clear vision on the evolution of the awareness process and on the strategies to adopt on digital transformation processes for the target group of the survey.

\section{CONCLUSIONS}

Digital transformation is not an end, but a powerful mean to accelerate the recovery of the CI. Implementation processes will always be painful, laborious and require a commitment from all parties involved.

To accomplish the goals of digital transformation in construction it is necessary to achieve the success at all levels on the highest number of implementation processes. Empathic technology, well embedded on the construction processes that deals with, streamlining them and obtaining the best from its users in terms of work power and motivation is a continuous challenge to have in mind. In addition and prior to start, strategic thinking using frameworks as the one presented must be established to assess the stakeholder's readiness and feelings towards the process. These can also be used for the process follow-up, working as success enablers.

Setting an overall digital transformation strategy to this group of stakeholders based on the combined results of both surveys, the first actions should aim increasing the maturity at "process dimension" in "Mobile Devices". In parallel, concerns should focus on increasing the maturity at all dimensions in "Connectivity" using an approach based on "process" dimension, this is, evidencing the processes in construction where this technology can be applied. Second level actions should work "Cloud computing" and "Information digitalization/metadata". "Systems integration/interoperability" and "Augmented reality" constitute a third action level as the second mentioned technology can benefit from high maturity levels at all dimensions of the first one.

The developed framework positions at a medium level. It is narrow than PESTEL analysis but provides broader results than dedicated strategies. Notwithstanding, it can be used either for a global/meso perspective on a group of technologies or focus on a single technology working individually the results of the distinct dimensions. The survey allowed the validation of the framework and more, as the outcomes prove to be valid for strategic approaches within the context of the respondents (country and type of stakeholder).

The next-steps will focus on answering some of the questions raised in the "Discussion" part as well as drawing strategic approaches for real implementation situations of one or more technologies using the results as guidelines.

The improvement and focus of the framework on specific topics is envisaged for the purpose of certain roles in the industry. One specific example are the cost engineers, top managers of construction companies and some BIM roles, where background and other frameworks have already been developed and tested. The same type of respondents in other countries constitutes also a future heading to evaluate the differences.

\section{ACKNOWLEDGMENTS}

The present research is being held under technical scientific cooperation agreement between Porto University Faculty of Engineering and the Brazilian Cost Engineering Council. The authors acknowledge these institutions for all the opportunities and work 
made so far under this agreement. This work was also financially supported by: Base Funding - UIDB/04708/2020 of the CONSTRUCT - Instituto de I\&D em Estruturas e Construções - funded by national funds through the FCT/MCTES (PIDDAC).

\section{REFERENCES}

Ali, A., \& Smith, D. (2019). Blockchain and mortgage lending process: A study of people, process, and technology involved. Online Journal of Applied Knowledge Management, 7(1), 53-66. https://doi.org/10.36965/ojakm.2019.7(1)53-66

Calvetti, D., Gonçalves, M. C., Magalhães, P. N. M., \& de Sousa, H. J. C. (2019). Sensing technologies embedding construction workers outcomes / key performance indicators. In B. Kumar, F. Rahimian, D. Greenwood, \& T. Hartmann (Eds.), In Proceedings of the 36th CIB W78 2019 Conference: Advances in ICT in Design, Construction and Management in Architecture, Engineering, Construction and Operations (AECO) (pp. 890-900). Newcastle, UK: ISBN (Print) 9781861354877, ISBN (eBook) 9781861354860.

Centre for Digital Built Britain. (2019). Developing the Capabilities for a Digital Built Britain. Cambridge. Retrieved from https://www.cdbb.cam.ac.uk/news/capabilityframework-and-research-agenda-digital-built-britain

Comission, E. (2012). Strategy for the sustainable competitiveness of the construction sector and its enterprises. Brussels.

Derenzi, D., De Sousa, P. S., De Oliveira, S. A., Herdeiro, M. A. N., Albernaz, J. R., \& Valadares, A. (2009). A successful approach in integrating people, process, and technology inside collaborative environments: A practical view of challenges and lessons learned. Digital Energy Conference and Exhibition 2009, 268-277. https://doi.org/10.2118/123287-ms

Desruelle, P., Baldini, G., Barboni, M., Bono, F., Delipetrev, B., Duch Brown, N., ... Urzi Brancati, M. C. (2019). Digital Transformation in Transport, Construction, Energy, Government and Public Administration. Seville. https://doi.org/10.2760/689200

Egan, S. J. (2000). Accelerating Change (Constructi). London: Rethinking Construction. Federation, F.-E. C. I. (2014). FIEC - Manifesto for Action Eu Term 2014-2019. Brussels.

Forum, W. E. (2016). Shaping the Future of Construction - A Breakthrough in Mindset and Technology. Geneva. Retrieved from https://www.weforum.org/reports/shapingthe-future-of-construction-inspiring-innovators-redefine-the-industry

Hjelseth, E. (2017). Bim understanding and activities. WIT Transactions on The Built Environment, 169, 3-14. https://doi.org/10.2495/BIM170011

KMPG - PMI. (2013). Study on Project schedule and cost overruns. Mumbai.

Martin Fischer, Howard W. Ashcraft, Dean Reed, A. K. (2017). Integrating Project Delivery. (I. Jonh Wiley \& Sons, Ed.). Hoboken, New Jersey: Jonh Wiley \& Sons, Inc.

Oesterreich, T. D., \& Teuteberg, F. (2016). Understanding the implications of digitisation and automation in the context of Industry 4.0: A triangulation approach and elements of a research agenda for the construction industry. Computers in Industry, 83, 121-139. https://doi.org/10.1016/j.compind.2016.09.006

Owen, R. (2013). Integrated Design \& Delivery Solutions ( IDDS ). Rotterdam.

PwC Portugal. (2016). Indústria 4.0 - Construir a empresa digital. Lisbon. Retrieved from www.pwc.pt/industria40

Rasmus Rempling, Esra Kurul, A. H. O. (2019). Information Integration in Construction Research Roadmap. Delft. Retrieved from https://site.cibworld.nl/dl/publications/pub417/Publ_417_TG90.pdf 
Richardson, D. (2014). Productivity in the Construction Industry. ASCE Eng Issues J Prof Act (Vol. 104). Canberra.

Sousa, H.; Mêda, P. (2016). A case study of Innovation and Strategic Governance School refurbishment program in Portugal. In 10th ICEC2016 - International Cost Engineering Council World Congress. Rio de Janeiro: Cost Engineering Council.

Sousa, H.; Mêda, P. (2017). Desafios Da Transformação Digital Da Fileira Da Construção. XXI Congresso Da Ordem Dos Engenheiros - Engenharia e Transformação Digital, 13.

Sriram Changali, Azam Mohammad, M. van N. (2015). The construction productivity imperative. McKinsey \& Company - Capital Projects \& Infrastructure. Retrieved from http://www.mckinsey.com/industries/capital-projects-and-infrastructure/ourinsights/the-construction-productivity-imperative

Succar, B., \& Kassem, M. (2015). Macro-BIM adoption: Conceptual structures. Automation in Construction, 57, 64-79. https://doi.org/10.1016/j.autcon.2015.04.018

Turk, Ž. (2019). Construction 4.0 - Digital Transformation of One of the Oldest Industries. Economic and Business Review, 21(3), 393-410. https://doi.org/10.15458/ebr.92

Yagiz, Kartal; Ustundag, Alp; Cevikcan, E. (2018). Industry 4.0: Managing The Digital Transformation. In S. International (Ed.) (Springer S, p. 286). Istambul: Springer International Publishing. https://doi.org/10.1007/978-3-319-57870-5 